\title{
The Application of High Q-value Load Resonant Power Supply in Intermediate Frequency Induction Furnace with Thick Lining
}

\author{
Lili Ding ${ }^{\mathrm{a}}$, and Jin $\mathrm{Hu}^{\mathrm{b}}$ \\ Aviation Maintenance NCO Academy, Xinyang, 464000, China \\ aemaillilac6212@sina.com, bbenchi9506@sina.com
}

Keywords: high Q-value load circuit; intermediate frequency induction power supply; power characteristics; induction heating; series resonance circuit; parallel resonant circuit.

\begin{abstract}
In order to solve the problem of excessively thin and overpower of ordinary medium frequency induction furnace lining, a main circuit with high Q-value and anomalous power characteristics is designed. It is applied to the field of induction heating, which can effectively increase the lining thickness, reduce the steel consumption, and will not bring high working voltage, working current and low efficiency, realizing the converting circuit of virtual work to the real work. The high the Q-value is, the more the abnormal power characteristics of the output power are. The main circuit effectively overcomes the difficult vibration of traditional parallel compensation circuit and the over-voltage of the power supply in series compensation.
\end{abstract}

\section{Introduction}

Comparing with the traditional arc heating method, the induction heating method has lots of advantages, such as energy saving, small pollution, low gas content of steel, less burning loss of alloy elements, electromagnetic stirring and precise control of temperature, and so on [1]. But the thin lining of induction furnace has limited its wide application. Because the thin lining reduces the life of the induction furnace lining material, limiting the use of the lining material, resulting in the loss of large scale smelting capacity of the induction furnace. Therefore, it will bring a series of benefits to induction furnace and greatly expand its application field if it is solved the problem of thin lining of induction furnace [2][3]. In this article we design a new circuit topology for induction heating medium frequency power supply. There are two excellent characteristics of the power supply after verification: high Q-value resonance and anomalous power output characteristics. It is analyzed the application prospect of the medium frequency induction furnace with this power supply.

\section{A Typical Medium Frequency Induction Furnace Lining}

Induction heating medium frequency furnace is a resonant system which $Q$-value can be defined as the ratio of the system virtual work power $P_{\mathrm{S}}$ to the real power $P$. That is $Q=P_{S} / P[4][5]$. The lower $Q$-value of the resonance system is better in the field of induction heating. For induction smelting, the furnace lining should not be too thick, otherwise, the power output of resonant system will be affected by the high $Q$-value of the induction furnace [6]. For the induction diathermy device, the resonant frequency is higher. Otherwise the system's $Q$-value will be increased due to the low resonant frequency, which will eventually lead to the decrease of output power. But the higher the resonant frequency of the induced diathermy system is, the more serious the skin effect in the thermal process will be [7]. And it will cause the heating of the billet to be uneven, which length of the induction hot line should be extended. It's all going to lead to an increase in production costs [8].

When the induction coil is inserted into the alternating current i with angular frequency $\omega$, the magnetic flux that generated by the coil will be divided into three parts [9]. Part of them is $\Phi_{1}$ that the flux is passing through the lining; part of them is $\Phi_{\mathrm{a}}$ that the flux is passing through furnace 
lining; the other part of them is the main magnetic flux $\Phi_{2}$ that is passing through the steel [10]. The eddy current produced $\Phi_{2}$ by the main magnetic flux is heating up steel. Leakage magnetic flux does not do the actual work of the load, only introducing the virtual work component. Because the thickness of induction furnace lining is decided by the leakage flux, the thicker the lining is, the bigger the Q-value is.

\section{Resonant Circuit}

Typical induction heating medium frequency power inverter is divided into series resonant circuit and parallel resonant circuit, as it is shown in Figure1. The characteristics of series resonant circuit are: (1) voltage resonance. The furnace voltage is equal to the input voltage, which is equal to $\mathrm{Q}$ times the resonance voltage. That is $\mathrm{U}_{\mathrm{L}}=\mathrm{U}_{\mathrm{C}}=\mathrm{QU}_{\mathrm{d}}$; (2) characteristic of constant power output. Although the increase of $\mathrm{Q}$ value (such as lining thickening) does not reduce the output power, it will result in a sharp increase in the furnace voltage and resonant voltage. In addition, the input direct current voltage is not too high. When the DC voltage $U_{d}$ is magnified, the furnace voltage $U_{L}$ is very high and very dangerous, so the high medium frequency induction furnace is not used in series resonant circuit.

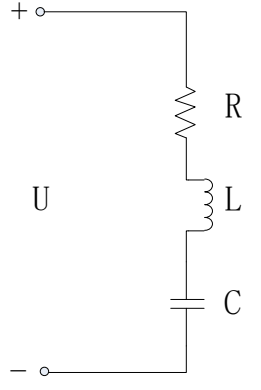

(a) series resonant circuit

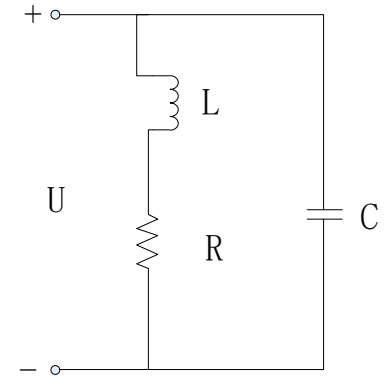

(b) parallel resonant circuit

Fig.1 The typical series resonant circuit and parallel resonant circuit

The characteristics of parallel resonant circuit are: (1) current resonance. The current in the LC resonant circuit is $\mathrm{Q}$ times the current flowing through the load resistor $\mathrm{R}$. But the furnace voltage that is equal to the resonant capacitor voltage is approximately equal to the input DC voltage. That is $\mathrm{U}_{\mathrm{L}}=\mathrm{U}_{\mathrm{C}} \approx \mathrm{U}_{\text {d. }}$. (2) With the increase of $\mathrm{Q}$ value (such as lining thickening), the output power of the furnace is decreased sharply. (3) In the parallel resonant, the load resistance is very low, and there is a severe vibration difficulty, so increasing the output power mainly depends on improving the furnace voltage.

According to the above characteristics, the lining thickness of the medium frequency induction furnace is about $1 / 10$ of the furnace diameter. The series resonance increases the lining thickness, which will lead to too high furnace voltage; while parallel resonance will bring sharp reduction of output power.

\section{Working Principle of the High Q-Value Load Resonant Power Circuit}

As shown in Figure 2, it is the main circuit of high Q-value resonant induction heating medium frequency power supply with abnormal power characteristic. It mainly consists of full wave rectification bridge of the thyristors that composed of rectifier thyristor $T_{3} \sim T_{8}$, the smoothing reactors $\mathrm{L}_{\mathrm{d} 1} \sim \mathrm{L}_{\mathrm{d} 2}$ and a inverter bridge. Through two independent half-wave rectifier bridge and the smoothing reactors $\mathrm{L}_{\mathrm{d} 1} \sim \mathrm{L}_{\mathrm{d} 2}$ filtering respectively, three-phase AC power frequency forms two current sources to supply $C_{1}$ and $C_{2}$ respectively. The inverter bridge consists of resonant capacitor $C_{1}$ and $C_{2}$, furnace induction coil $L$, isolation capacitor $C d$, and thyristors $T_{1}$ and $T_{2}$. Among them, $\mathrm{D}_{1}$ and $\mathrm{D}_{2}$ are respectively reverse parallel continuation diodes. It can be reduces to the circuit diagram shown in Figure 3. 


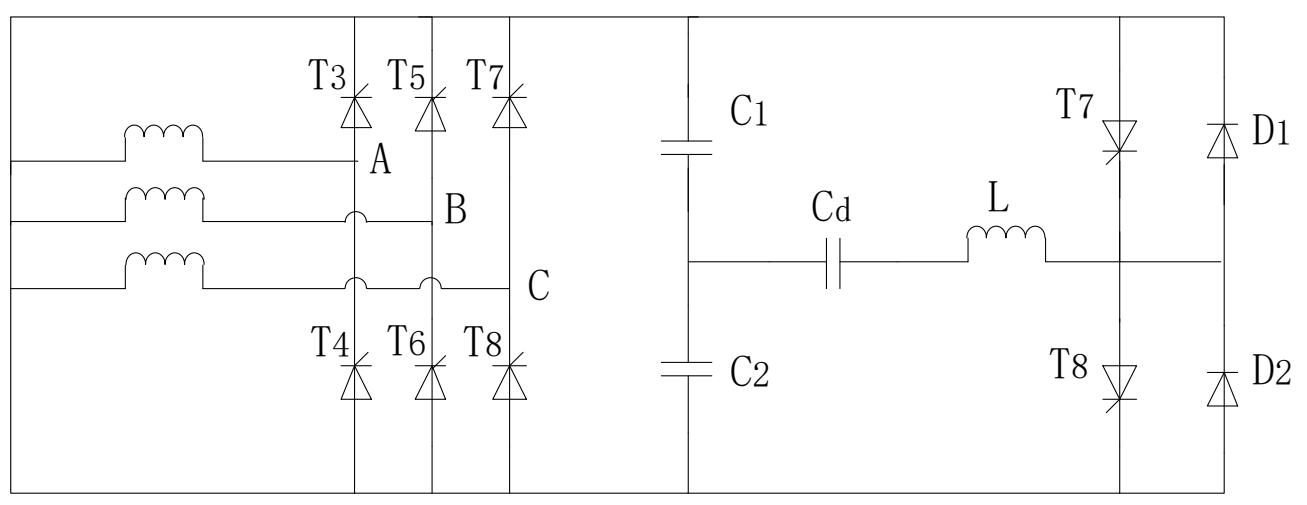

Fig. 2 The main circuit of high Q-value load resonant power supply

The main circuit includes DC voltage source $\mathrm{E}$ and filter reactor I, DC current source I, resonant capacitor $C_{1}$ and $C_{2}$, furnace induction coil $L$, and thyristor $T_{1}$ and $T_{2}$. Under the resonant state, when the T1 turns on and T2 shuts off, two loops do together the current's half wave shock; when $\mathrm{T} 2$ turns on and T1 shuts off, the other loops complete the current's negative half wave current shock.

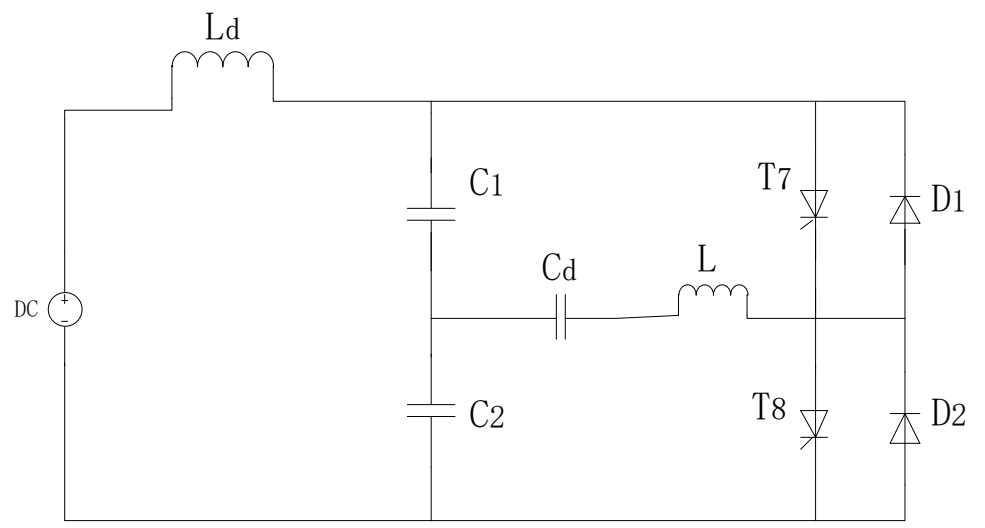

Fig. 3 The equivalent circuit diagram of high Q-value load resonant power supply

\subsection{Resonant Characteristics of High Q-Value.}

Because this power supply can convert parts of the virtual work into real work, it has lower Q-value compensation characteristics, and the specific measurement results are shown in Table 1. Table: $\mathrm{N}$ is the ratio of the lining thickness $\mathrm{d}$ to the furnace diameter $\mathrm{D}$; the traditional measurement method of Q-value is to measure the a typical parallel resonance circuit which includes induction coil L and the resonant capacitor C; The K-value is the ratio of Ps to PR measured on this device.

Tab. 1 Characteristics of high Q-value

\begin{tabular}{|c|c|c|c|}
\hline $\mathrm{d} / \mathrm{mm}$ & $\mathrm{Q}$ & $\mathrm{Q}$ & $\mathrm{K}$ \\
\hline 100 & 0.1 & 2.6 & 1.12 \\
\hline 200 & 0.23 & 4.1 & 1.67 \\
\hline 300 & 0.45 & 5.9 & 2.98 \\
\hline
\end{tabular}

Controlled by the resonant characteristics of the high $\mathrm{Q}$ value, the voltage compensation circuit is with obvious characteristics which has nothing to do with the

K-value of the equipment. It is similar with the series resonant. But the voltage compared with the series resonant frequency, output voltage of this circuit is less than the series resonant circuit $1 / 4$. 


\subsection{Abnormal Power Output Characteristics.}

The intermediate frequency induction furnace has the abnormal power output characteristics which has thicker lining and the higher output power, and the test results are shown in Table 2. With this unique abnormal power output characteristics, the lining of medium frequency induction furnace can be made very thick without reducing its power output.

Tab. 2 Characteristics of power output

\begin{tabular}{|c|c|c|}
\hline $\mathrm{d} / \mathrm{mm}$ & $\mathrm{Q}$ & $\mathrm{P} / \mathrm{W}$ \\
\hline 100 & 2.6 & 2653 \\
\hline 200 & 4.1 & 4368 \\
\hline 300 & 5.9 & 6869 \\
\hline
\end{tabular}

\section{Application of Induction Furnace with Low Voltage and Large Tonnage}

The series inverter medium frequency power supply has the voltage compensation characteristic, and the furnace body voltage is very high. In order to improve the success rate of the parallel inverter medium frequency power supply, it is necessary to increase the voltage, otherwise it will be restricted by the damping law of the parallel resonant system, and the vibration will be difficult. Since the peak voltage of domestic 10t intermediate frequency induction furnace has reached $8 \mathrm{kV}$, the highest withstand voltage of induction furnace coil produced by the leading American company is only $15 \mathrm{kV}$, which does not consider the safety of personnel. Therefore, it is difficult to increase the power of the equipment only by increasing the voltage, so it is difficult to manufacture the $10 \mathrm{t}$ intermediate frequency electric furnace.

This new type of power supply does not have the same vibration trouble as the common series inverter medium frequency power supply, But the special voltage compensation characteristic and the high $\mathrm{Q}$ value resonance characteristic make this equipment under the same Q-value and the output power, the intermediate frequency voltage is smaller than the common series inverter intermediate frequency power supply voltage 1/4.Using the original high Q-value resonant intermediate frequency power supply technology, the peak value of the 50t induction furnace body can be controlled at $4 \sim 5 \mathrm{kV}$.

\section{Conclusion}

A new circuit topology induction heating medium frequency power supply is designed in this paper. The characteristics of high Q-value resonant medium frequency induction heating power supply and the superiority of double layer structure lining are verified by experiments. The thickness of medium frequency induction furnace lining has great economic value in the large capacity of smelting, smelting, induction heating, and so on.

\section{References}

[1] Zhao Jian. Research status quo fo energy saving technology for medium frequency induction melting furnace [J]. Industrial Heating, 2016, 1:52-54.

[2] Wang Yong, Yuan Qingying, Wang Yicen, Chang Yongle. Analysis on Energy-saving Effectiveness of Application of Series Resonance Medium Frequency Power Supply to Pipe Induction Heating [J]. Steel Pipe, 2015, 44(2):79-82.

[3] Hu Fengge, Wu Xusheng, Nie Ziling. Harmonic ananlysis of output voltage in matrix converter based medium frequency supply [J]. Journal of Naval University of Engineering, 2017, 29(2):32-36.

[4] Wu Shuigui. The application of IGBT medium- frequency power source in vacuum induction smelting furnace [J]. Technology Wind, 2011, 23:95-96,104.

[5] Yuan Fang, Zhang Yi, Xi Yuzhen, Zhou Kai, Wang Chengyu. Preparation of Paraffin Emulsion 
and Its Application in Wood Processing [J]. Guangdong Chemical Industry, 2017, 44(12):1-3.

[6] Zhang Shulliang. Characteristics of induction heating furnace [J]. Special Steel Technology, 2017, 23(1):23-23.

[7] Peng Yonglong, Shi Meng, Li Yabing, Jiang Tao. Application of SIC MOSFET in induction heating power supply. Electrical Measurement \& Instrumentation [J], 2017, 54(12):112-116.

[8] Li Zhijun, Xiang Linbo, Xiao Wenrun. Universal mem-elements emulator and its application in PLC circuit [J]. Journal of Electronics \& Technology, 2017, 39(7):1626-1633.

[9] Sun Jianliang, Qiu Chouwu, Bi Xuefeng, Wang Shi. Study on heating effect of heavy cylinder with induction heating and conventional heating [J]. Chinese Journal of Mechanical Engineering, 2017, 53(10):25-33.

[10] Zhang Liang. Design of induction heating power supply system of dual microprocessor based on MCU and FPGA [J]. Power Electronics, 2017, 51(6):92-94. 